Historic, archived document

Do not assume content reflects current scientific knowledge, policies, or practices. 


\section{AN IMPROVED METHOD FOR REARING THE ANGOUMOIS GRAIN MOTH}

ARS-S-104

March 1976 


\section{CONTENTS}

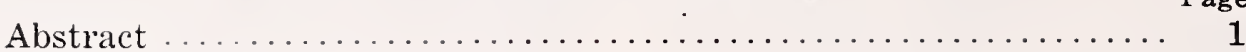

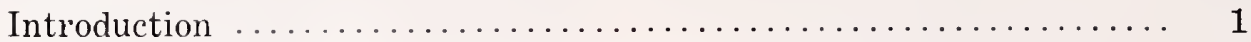

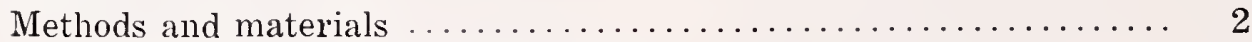

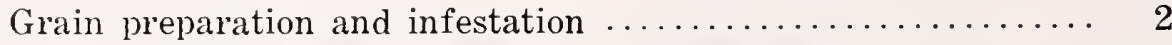

Collection and dispensation of adults for oviposition .......... 2

Oviposition, and collection and cleaning of eggs .......... 3

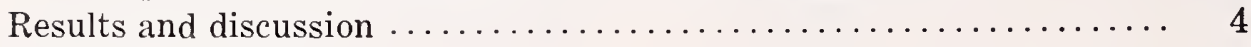

Acknowledgments .............................. 5

\section{ILLUSTRATION}

Fig.

1. Suspended Sitotroga cerealella moth production unit ......... 2

\section{TABLE}

1. Quantities of Angoumois grain moth adults and eggs produced in a 4 -month period from $9.7 \mathrm{~kg}$ of wheat infested daily ..........

Trade names are used in this publication solely for the purpose of providing specific information. Mention of a trade name does not constitute a guarantee or warranty of the product by the U.S. Department of Agriculture or an endorsement by the Department over other products not mentioned. 


\title{
AN IMPROVED METHOD FOR REARING THE ANGOUMOIS GRAIN MOTH
}

By R. K. Morrison ${ }^{1}$ and J. D. Hoffman²

\begin{abstract}
An improved method for the production of eggs of the Angoumois grain moth [Sitotroga cerealella (Olivier)] was developed. During a 136-day test, a daily average of $127 \mathrm{~g}$ of eggs (about $6.6 \mathrm{million}$ ) was produced. This production level required that $9.7 \mathrm{~kg}$ of clean wheat be heavily infested each day with Angoumois grain moth eggs. The wheat was promptly disposed of after emergence of the first brood of adults. About $12 \%$ of the eggs produced daily $(790,000)$ were returned for culture maintenance. This method essentially eliminated the contamination and irregular production experienced by earlier methods that used the same rearing medium for producing several generations of Angoumois grain moths.
\end{abstract}

\section{INTRODUCTION}

Experimental data from mass releases of Chrysopa carnea (Stephens) ${ }^{3}$ and Trichogramma* spp. have demonstrated the potential of these entomophagous insects for insect pest control. ${ }^{5}$ Previously, most methods of Trichogramma production have used eggs of the Angoumois grain moth, Sitotroga cerealella (Olivier),${ }^{6}$ as a host. ${ }^{7} C$. carnea has also been successfully reared using Angoumois grain moth eggs as food. ${ }^{8}$ However, the expense and reliability of consistently producing adequate numbers of moth eggs have been major limitations in mass producing these entomophagous insects

1 Research entomologist, Cotton Insects Research Laboratory, Agricultural Research Service, U.S. Department of Agriculture, P.O. Drawer DG, College Station, Tex. 77840 .

2 Research entomologist, Biological Control of Insects Research Laboratory, Agricultural Research Service, U.S. Department of Agriculture, Columbia, Mo. 65201.

3 Neuroptera:Chrysopidae.

+ Hymenoptera:Trichogrammatidae.

5 Ridgway, R. L. and Jones, S. L. 1969. Inundative releases of Chrysopa carnea for control of Heliothis on cotton. J. Econ. Entomol. 62 (1) : 177-180. Parker, F. D., Lawson, F. R., and Pinnell, R. E. 1971. Suppression of
(Flanders; Spencer, Brown, and Phillips; cited in footnote 7).

Previous methods of producing Angoumois grain moth eggs required large amounts of grain. The entire amount was infested over a short period with small numbers of Angoumois grain moth eggs in the expectation that the remaining uninfested grain would gradually be infested by succeeding generations of adults produced within a production unit prior to their removal for ovipositional purposes. Grain held in this system over extended periods invariably became contaminated with other stored grain pests and the straw itch mite, Pyemotes ventricosus. ${ }^{9}$ The presence of this mite resulted in serious or com-

Pieris rapae using a new control system: Mass release of both the pest and its parasites. J. Econ. Entomol. 64 (3) : 721-735.

${ }^{6}$ Lepidoptera:Gelechiidae.

7 Flanders, S. E. 1930. Mass production of egg parasites of the genus Trichogramma. Hilgardia 4 (16) : 465501. Spencer, H., Brown, L., and Phillips, A. M. 1935. New equipment for obtaining host material for mass production of Trichogramma minutum, an egg parasite of various insect pests. U.S. Dep. Agric. Circ. 376, 17 pp.

s Ridgway, R. L., Morrison, R. K., and Badgley, M. 1970. Mass rearing a green lacewing. J. Econ. Entomol. 63 (3) : 834-836.

9 Acarina: Pyemotidae. 
plete losses in production as well as major human discomfort since it preys on humans as well as insects (Flanders; Spencer, Brown, and Phillips; cited in footnote 7 ). This study was undertaken to eliminate these problems and achieve consistent daily production at predictable levels.

\section{METHODS AND MATERIALS}

\section{Grain Preparation and Infestation}

Soft red winter wheat was selected as the rearing medium because of low cost and availability. In order to kill any pests present in the grain before use, it was fumigated with methyl bromide for $24 \mathrm{~h}$ at $26^{\circ} \mathrm{C}$ at the rate of $13 \mathrm{~g} / \mathrm{m}^{2}$ and then ventilated for $12 \mathrm{~h}$ with fresh air. After ventilation, $9.7 \mathrm{~kg}$ of pest-free grain was mixed with $4 \mathrm{~g}$ of $35 \%$ dicofol wettable powder dispersed in $1.25 \mathrm{I}$ of water for $30 \mathrm{~min}$ to prevent possible reinfestation by mites. The grain was then loaded into a 24 - by 48 - by $3 / 4$-inch open-top crib (fig. 1).

The crib was made from a 24 - by 97 -inch piece of 10-strand-per-inch hardware cloth bent in a $U$-shape around four wooden slats $(3 / 4$ by $3 / 4$ by 48 inches) placed parallel with each other on 8-inch centers. Heavy-duty 1/2-inch staples fastened the hardware cloth to the wooden slats so that, when the crib was filled, the wheat was uniformly distributed from top to bottom.

Prior to infestation of the wheat, 24- to 48-hold Angoumois grain moth eggs were treated with a $10 \%$ solution of formalin for $4 \mathrm{~min}$ to eliminate possible mite infestation. Following treatment, the eggs were washed for $10 \mathrm{~min}$ in running water to deactivate the formaldehyde. Then $15 \mathrm{~g}$ of eggs was placed in a $250 \mathrm{ml}$ wash bottle, which was filled with water and fitted with a simple laundry sprinkler.

Infestation of the wheat was accomplished by placing the crib in a flat horizontal position and sprinkling the eggs evenly over the top side of the hardware-cloth-covered wheat. The infested crib was then placed in a horizontal storage rack for 10 days to allow for egg hatch and subsequent larval infestation of the grain. On the 11th day, the crib was removed and placed in a vertical position on a floor rack. The rack was designed to separate any additional cribs by about 6 inches to allow for adequate air circulation.

Excessive metabolic heat that can cause larval estivation was controlled by removing a crib 15

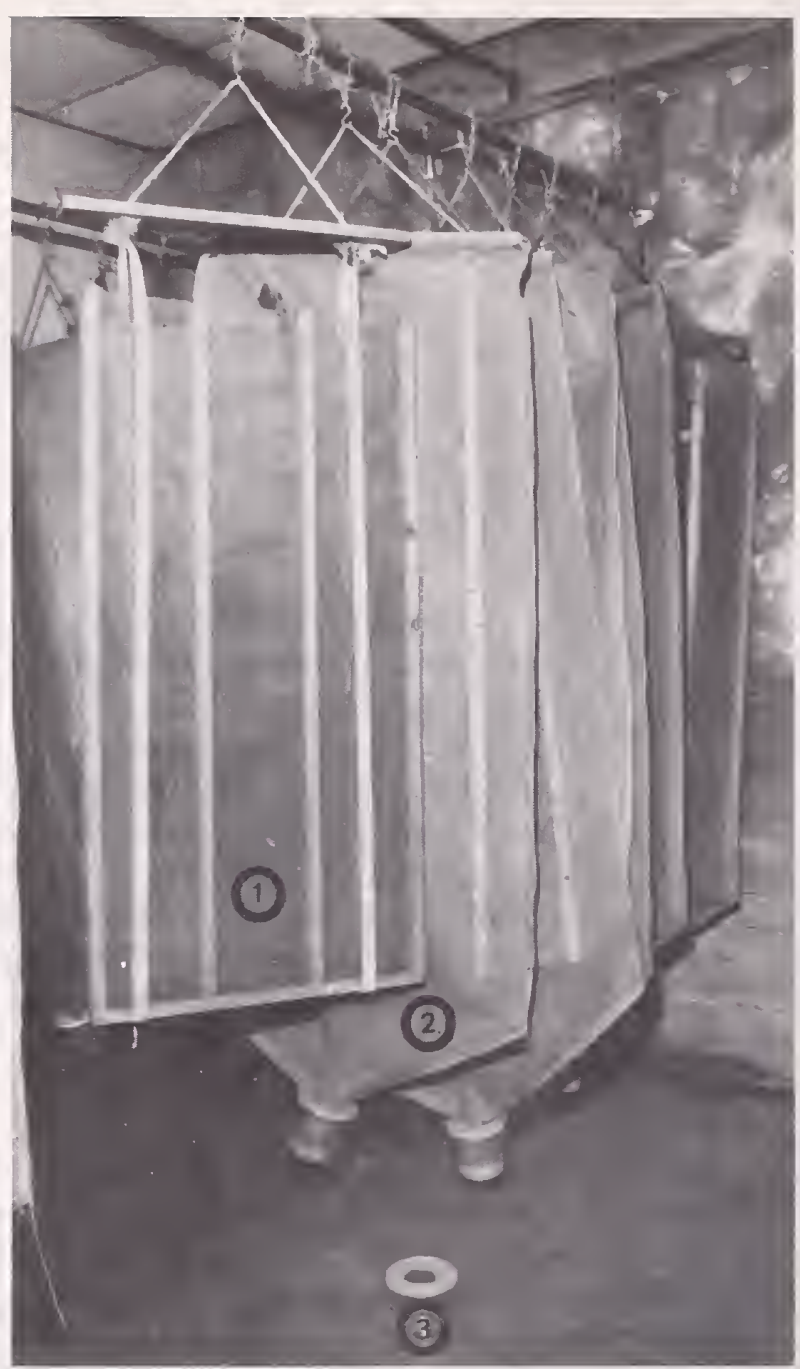

FIGURE 1.-Suspended Sitotroga cerealella moth production unit. (1) Crib with larval infested grain in suspension sling. (2) Crib enclosure bag. (3) Adult collection container.

days after infestation, immersing it in a water bath for $5 \mathrm{~s}$, draining the water, and then replacing it on the rack.

\section{Collection and Dispensation of Adults for Oviposition}

Adult collection began 23 days after infestation, at which time the crib was taken to an adult collection room and placed in a collection device (fig. 1) which consisted of (1) a sling for suspension of the crib, (2) a plastic screen bag to enclose the crib, and (3) an adult collection container.

The sling was constructed from two pieces of 
cotton webbing (1 inch wide) 102 inches in length. The pieces of webbing were placed around the crib near each outer edge with each piece being overlapped 2 inches at the top and riveted together to form two loops. The ends of a piece of $3 / 8$-inch manila rope (40 inches in length) were then inserted through $3 / 8$-inch holes drilled along the center length of a 28- by 4- by 1 -inch board 6 inches from each end and tied to the loops. The center point of the rope was then placed on an S-hook which was attached to a 1-inch-diameter pipe suspended horizontally from the ceiling at a height of $8 \mathrm{ft}$. A crib placed in the loops of the sling was thereby held suspended about 18 inches above the floor.

With the crib in place in the sling, a 13-strandper-cm plastic screen-enclosing bag was drawn up and over the crib and tightly stapled at the top to the sling-supporting board. The bag was made from a piece of 6 -ft-wide plastic screen about 68 inches long that was sewn to form a 6 -ft-long tube with a circumference of 66 inches. One end of the tube was pressed flat and sewn to form a 12-inch cone whose apex was at the center of the flattened tube. An open-end plastic cylinder $12 \mathrm{~cm}$ long and $6 \mathrm{~cm}$ in diameter passed through the apex of the cone and glued in place to the plastic screen served to funnel the moths into the attached adult collection container. The collection container was a 1-qt polystyrene container with a 5 -cm circle cut out from the lid. The cutout lid with the attached container was easily forced over the cylinder on the bag and held in place by friction.

The moths were collected and weighed each $24 \mathrm{~h}$ for 27 days. Each day the outside of the bag was lightly brushed and briefly shaken; the moths clinging to the bag and crib were dislodged and fell into the collection container. The container was removed, replaced by an empty one, and then the moth weight determined. After 27 days of collection, the crib, screen bag, and suspension sling were removed from the room, fumigated with methyl bromide, washed after discarding the wheat, and then returned to use.

\section{Oviposition and Collection and Cleaning of Eggs}

The oviposition cage for Angoumois grain moths consisted of a frame (36 by 28 by 1 inch) made from $3 / 1$-inch plywood. One side of the frame was covered with a 13-strand-per-cm plastic screen, and the other side was covered with 8-strand-per-cm nylon screen. To facilitate introduction and removal of moths, a 6 - by 6 - by $1 / 4$-inch piece of plywood was nailed to one corner of the frame on the plastic screen side and the screen glued to the plywood. A 2-inch-diameter hole was cut through the center of the plywood and screen and closed with a large rubber stopper.

About 75,000 moths 0 to $24 \mathrm{~h}$ old, with an average male:female ratio of $1: 1$, were placed in each oviposition cage. This density level facilitated optimum oviposition rates and ease of handling. After placing the moths in the cage it was positioned with the nylon screen side down on a 40 - by 30 -inch galvanized sheet-metal pan (26 gage) that had been lightly dusted with sifted wheat flour. The cage and pan were then placed together on a horizontal storage rack for $72 \mathrm{~h}$. During this period the female moths deposited eggs through the screen into the pan containing the flour. Each $24 \mathrm{~h}$ during the oviposition period the eggs were collected by raising the cage and vigorously brushing the nylon screen with a 3 -inch paint brush to dislodge any eggs clinging to the screen. After brushing, the cage was raised about 4 inches above the pan and briefly shaken to allow the loosened eggs to fall onto the pan. The cage was then temporarily laid aside and the eggs and flour brushed off the pan. The pan was then refloured, the cage replaced, and the unit returned to the storage rack. After being processed three times, the cage was removed, washed and dried after discarding the moths, and returned to use.

Each day the egg and flour mix was placed in a U.S. standard testing sieve series with sieve Nos. 30, 40, 50, and 60. The sieves, catch pan, and lid assembly were placed on an automatic sieve shaker for about $5 \mathrm{~min}$, or until all the flour passed through the No. 60 sieve. The flour was then discarded. A few egg clusters would not pass through the No. 30 sieve. To facilitate separation of these clusters, they were placed in an 18- by 18- by 2-inch wooden frame with an organdy cloth bottom. The cloth was slightly dampened with water, and the clusters were lightly brushed over the damp surface with a 1-inch camel hair brush until dry. This process provided adequate separation of the clusters. All eggs were then combined and passed through a 
current of air several times to remove any remaining debris.

A temperature of $26^{\circ} \pm 2^{\circ} \mathrm{C}$ and a relative humidity of $75 \% \pm 5 \%$ were maintained in all rearing areas. Lights were used only when rearing areas were occupied by working personnel. The total rearing operation consisted of two rooms 11 by $12 \mathrm{ft}$, one room 12 by $12 \mathrm{ft}$, and a multipurpose area of about $100 \mathrm{ft}^{2}$.

All workers wore a pair of $3 \mathrm{M}$ brand filter masks in rearing areas for protection against insect scales.

\section{RESULTS AND DISCUSSION}

The infestation of one production unit per day over a 136-day production period produced an average of $661 \mathrm{~g}$ (404-845 g) of adults per day (table 1 ). These adults produced an average of $127 \mathrm{~g}$ (58-182 g) of eggs per day; however, the low production periods were directly related to mechanical failure of temperature and humidity control equipment. Temperatures $4^{\circ} \mathrm{C}$ above optimum $\left(26^{\circ} \mathrm{C}\right)$ and relative humidities $45 \%$ below optimum $(75 \%)$ were recorded for periods up to $18 \mathrm{~h}$ during low egg production periods. Improved climatic controls should eliminate these problems.

Use of the dicofol-water treatment of the wheat prior to infestation increased grain moisture to about $20 \%$, which was the most favorable level for larval penetration ${ }^{10}$ and also provided protection against possible mite contamination. The formalin treatment of the eggs also functioned as a safeguard against the straw itch mite. Neither treatment adversely affected Angoumois grain moth egg hatch and essentially eliminated possible mite infestations. Eggs handled in this manner were about $75 \%$ viable, and the wheat infestation process resulted in about 0.7 of an adult being produced per grain of wheat. (The figures used in this calculation were based upon an average of 52,000 eggs/g, $260 \mathrm{moths} / \mathrm{g}$, and 29 grains of wheat/g.)

Temperatures of $35^{\circ} \mathrm{C}$ and higher occurred in the production units between the 16 th and 20 th day postinfestation when the units were not im-

11 Wilkinson, J. D., and Morrison, R. K. 1972. Effect of grain treatment and infestation level on larval infestation and adult emergence of the Angoumois grain moth, Sitotroga ccrealclla, reared in wheat. J. Econ. Entomol. 65 (1) : 264-268.
TABLE 1.-Quantities of Angoumois grain moth adults and eggs produced in a 4-month period from $9.7 \mathrm{~kg}$ of wheat infested daily

\begin{tabular}{|c|c|c|c|}
\hline & $\begin{array}{c}\text { Week } \\
\text { beginning }\end{array}$ & $\begin{array}{l}\text { Grams of adults } \\
\text { producing eggs } \\
\text { (daily avg.) }{ }^{1}=\end{array}$ & $\begin{array}{l}\text { Avg. daily egg } \\
\text { yield (grams) }\end{array}$ \\
\hline Oct. & $31 \ldots \ldots \ldots$ & 687 & 107 \\
\hline \multirow[t]{4}{*}{ Nov. } & $7 \ldots \ldots \ldots$ & 845 & 121 \\
\hline & $14 \ldots \ldots \ldots$ & 634 & 104 \\
\hline & $21 \ldots \ldots \ldots \ldots$ & 628 & 125 \\
\hline & $28 \ldots \ldots \ldots$ & 611 & 112 \\
\hline \multirow[t]{4}{*}{ Dec. } & $5 \ldots \ldots \ldots$ & 717 & 125 \\
\hline & $12 \ldots \ldots \ldots$ & 726 & 132 \\
\hline & $19 \ldots \ldots \ldots$ & 736 & 142 \\
\hline & 26 & 622 & 131 \\
\hline \multirow[t]{5}{*}{ Jan. } & $2 \ldots$ & 654 & 120 \\
\hline & $9 \ldots \ldots \ldots$ & 639 & 108 \\
\hline & $16 \ldots \ldots \ldots$ & 404 & 107 \\
\hline & $23 \ldots \ldots \ldots$ & 465 & 76 \\
\hline & $30 \ldots \ldots \ldots$ & 708 & 115 \\
\hline \multirow[t]{4}{*}{ Feb. } & $6 \ldots \ldots \ldots$ & 759 & 162 \\
\hline & $13 \ldots \ldots \ldots$ & 741 & 161 \\
\hline & $20 \ldots \ldots \ldots$ & 698 & 151 \\
\hline & $27 \ldots \ldots \ldots \ldots$ & 704 & 167 \\
\hline \multirow[t]{2}{*}{ Mar. } & $6 \ldots \ldots \ldots$ & 581 & 146 \\
\hline & verage...... & 661 & 127 \\
\hline
\end{tabular}

${ }^{1}$ An additional $3,000 \mathrm{~g}$ of adults was produced and used for experimental purposes other than egg production.

$\because$ About 250 moths $/ \mathrm{g}$.

${ }^{3}$ About 52,000 eggs/g.

mersed in water at 15 days postinfestation. Angoumois grain moth larvae exposed to these temperatures ceased feeding and development (estivated)." When this occurred, production was erratic, and much longer periods of time were required to obtain optimum production of adults. The water immersion technique prevented estivation and allowed maximum production of adults in 27 days.

Preliminary oviposition tests conducted in small oviposition cages of about $135 \mathrm{~cm}^{2}$ indicated no significant differences at the $5 \%$ level in numbers of eggs produced per female at moth density levels of $26,39,51$, and $63 \mathrm{mg} / \mathrm{cm}^{2}$. However, these density levels yielded significantly fewer eggs than a moth density level of 14 $\mathrm{mg} / \mathrm{cm}^{2}$, but the differences were not very great.

1 Unpublished data, K. D. Biever, research entomologist, Biological Control of Insects Research Laboratory, Agricultural Research Service, U.S. Department of Agriculture, Columbia, Mo. 65201. 
Therefore, a density level of 40 to $50 \mathrm{mg} / \mathrm{cm}^{2}$ was chosen for production to facilitate handling the number of moths produced daily and for more efficient production of eggs from the oviposition cage used in daily production.

Decontamination of grain and equipment before use, a high initial infestation rate of the grain, and a rapid one-generation population turnover, followed by prompt decontamination of spent grain and equipment resulted in effective, reliable, and continuous production of Angoumois grain moth eggs at a relatively high rate. Although the present study was a small developmental operation, the basic techniques could be readily adapted for an expanded mechanized system for mass production of the Angoumois grain moth.

\section{ACKNOWLEDGMENTS}

Grateful acknowledgment is made to $\mathrm{E}$. $\mathrm{K}$. Henry for his technical assistance during the development of these methods and to P. D. Lingren and S. L. Jones for their assistance in the preparation of this manuscript. 
U. S. DEPARTMENT OF AGRICULTURE AGRICULTURAL RESEARCH SERVICE SOUTHERN REGION P. O. BOX 53326

NEW ORLEANS. LOUISIANA 70153

OFFICIAL BUSINESS

POSTAGE AND FEES PAID

U. S. DEPARTMENT OF AGRICULTURE AGR 101

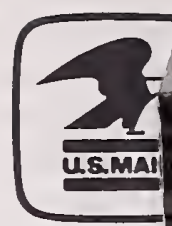

PENALTY FOR PRIVATE USE, \$300 